\title{
Editorial:
}

\section{Discovery of "Aligarh Super Bug" and Widespread variants of NDM1: A concern in antimicrobial resistance}

\author{
Rahman $S Z^{1}$, Mishra $A^{2}$
}

Bangladesh Journal of Medical Science Vol. 16 No. 03 July'17. Page : 335- 336

In clinical and non-clinical settings, bacteria are increasingly becoming resistant to prevalent antibiotics. Previously, this concern was for Gram-positive bacteria, particularly methicillinresistant Staphylococcus aureus and vancomycinresistant Enterococcus spp. These days, however, multidrug-resistant Gram-negative bacteria pose the greatest risk to public wellbeing. Not only are the Gram-negative bacteria developing resistance faster than Gram-positive bacteria, but also there are few antibiotics active against Gram-negative bacteria $^{1,2}$ and drug development programs are moving at much slower pace, insufficient to provide therapeutic cover in coming years. The resistance of Gram-negative bacteria is primarily because of mobile genes (plasmids) that can readily propagate through bacterial populations. Unprecedented human migration and travels allow bacterial plasmids to be transported rapidly across continents ${ }^{3}$.

Carbapenems are a class of beta-lactam antibiotics that are capable of killing most bacteria by inhibiting the synthesis of one of their cell wall layers. The carbapenems were developed to overcome antibiotic resistance mediated by bacterial betalactamase enzymes. However, a new type of carbapenem resistance gene, termed as $b l a_{\mathrm{NDM}-1}$ was reported in 2009 by D Yong et al. ${ }^{4}$ The $b l a_{N D M-1}$ gene forms NDM-1, which is a carbapenemase betalactamase-enzyme that inactivates carbapenem antibiotics. Detection of NDM-1 gene is based upon the phenotypic determination of enzyme activity ${ }^{3}$. These enzymes are zinc dependent and are termed as metallo-beta-lactamase.NDM-1 was first detected in a Klebsiella pneumoniae and Escherichia coli with bla ${ }_{\mathrm{NDM}-1}$ on plasmids from an in vitroisolate of a Swedish patient of Indian origin in 2008 after hospital admission in New Delhi, India ${ }^{5}$. Hence got the name, "New Delhi Metallo-beta-lactamase-1 (NDM1), an enzyme that makes bacteria resistant to a broad range of beta-lactam antibiotics and is readily transferred between bacterial strains.NDM-1 $\beta$-lactamase was later detected in Pakistan, Canada, United Kingdom, United States of America and Balkans. A total of 17 different variants of NDM1 have been identified, having variations at different site of their primary protein structure. These variants have varying catalytic activity against carbapenem.

From our municipal city Aligarh, a team of scientists led by AsadU Khan et al., reported a NDM-4producing Escherichia coli in the sewage of Jawaharlal Nehru Medical College Hospital (JNMCH) ${ }^{6}$. They also reported NDM-1producing C. lapagei in a preterm baby admitted to the Intensive Care Unit of JNMCH, Aligarh, India ${ }^{7}$.The editor of The Lancet, apologized that naming a superbug after New Delhi was wrong. Following this, Ajai R. Singh, editor of Mens Sana Monographs, proposed changing NDM-1 to PCM (plasmid-encoding carbapenem-resistant metallo-beta-lactamase) $)^{8}$. Similarly, "Aligarh Super Bug" would come under PCM.

Present strategies of combating the emergence and spread of multi drug resistance depends on the discovery of newer agents ${ }^{9}$, reduction in antibiotic induced bacterial mutation ${ }^{10}$, use of combinations

1. Syed Ziaur Rahman, Department of Pharmacology, Jawaharlal Nehru Medical College, Aligarh Muslim University, Aligarh 202002, India.

2. Ankita Mishra, Department of Pharmacology, Jawaharlal Nehru Medical College, Aligarh Muslim University, Aligarh, India.

Correspondence to: Syed Ziaur Rahman, Department of Pharmacology, Jawaharlal Nehru Medical College, Aligarh Muslim University, Aligarh 202002, India.email: rahmansz@yahoo.com,dr.ankitamishra@yahoo.com 
therapy ${ }^{11-12}$, early intensive (frontline) therapy ${ }^{13}$, and lately, surveillance of hypermutable organisms ${ }^{14}$ and targeting regulating functions necessary for infection $^{15}$. The selective use of probiotics and prebiotics and the deliberate refocus on narrowspectrum as opposed to broad-spectrum antibiotics in clinical practice can also help in the current scenario. Antibiotic resistance is continuously evolving to attain higher antibiotic resistance exhibiting elevated bacterial genetic evolution. The preventive measures are proving increasingly inadequate in the existing global scenario of MDR.

\section{Conclusion:}

The "superbugs" have attained the status of community acquired pathogens. The capability for wider international spread and for NDM-1-encoding plasmids to become an endemic pathogen worldwide, are very much there and frightening. Because of the significant lag time between the discovery and introduction of new anti-infective agents and the need for new discovery of alternative solutions, all physicians should refocus on the appropriate and judicious use of antibiotics in any clinical settings ${ }^{15}$.

\section{References:}

1. Tan TT.'Future" threat of Gram-negative resistance in Singapore, Ann Acad Med Singapore 2008; 37: 884890.

2. Baiden F, Owusu-Agyei S, Webster J, Chandramohan D. The need for new antibiotics; Lancet. 2010; 375, 637-638. https://doi.org/10.1016/S0140-6736(10)60265-6

3. Kumarasamy KK, Toleman MA, Walsh TR, et al. Emergence of a new antibiotic resistance mechanism in India, Pakistan, and the UK: a molecular, biological, and epidemiological study. Lancet Infect Dis. 2010; 10 (9): 597-602. https://doi.org/10.1016/S1473-3099(10)70143-2

4. Yong D, Toleman MA, Giske CG.Characterization of a new metallo- $\beta$-lactamase gene, blaNDM-1, and a novel erythromycin esterase gene carried on a unique genetic structure in Klebsiella pneumoniae sequence type 14 from India. Antimicrob Agents Chemother. 2009; 53, 5046-5054. https://doi.org/10.1128/AAC.00774-09

5. Queenan AM, Bush K. Carbapenemases: the Versatile $\quad \beta$-Lactamases. Clinical Microbiology Reviews. 2007;20(3):440-458. https://doi.org/10.1128/CMR.00001-07

6. Khan AU, Parvez S. Detection of blaNDM-4 in Escherichia coli from hospital sewage. J. Med Microbiol 2014; 63: 1404-6 https://doi.org/10.1099/jmm.0.076026-0

7. Ahmad N, Ali SM, Khan AU. First reported New Delhi metallo-ßlactamase-1-producing Cedecea lapagei,Int. J. Antimicrob. Agents 2017; 49:118-119. https://doi.org/10.1016/j.ijantimicag.2016.10.001

8. Science, names giving and names calling: Change NDM-1 to PCM". Mens Sana Monographs. Retrieved April, 2016.

9. Wright GD. Making sense of antisense in antibiotic drug discovery. Cell HostMicrobio 2009; 197-198.

10. CouceA, Blázquez J. Side e $\square$ ects of antibiotics on genetic variability. FEMSMicrobiol.Rev. 2009; 33: 531-538. https://doi.org/10.1111/j.1574-6976.2009.00165.x

11. DeCristóbal RE, VincentPA, Salomón RA.Acombination of sbmA and tolC mutations in Escherichia coli K-12 Tn10-carrying strains results in hyper susceptibility to tetracycline. J. Bacteriol. 2008; 190: 1491-1494. https://doi.org/10.1128/JB.01844-07

12. Motter AE. Improved network performance via antagonism: from synthetic rescues to multidrug combinations. Bioassays 2010; 32: 236-245. https://doi.org/10.1002/bies.200900128

13. Carattoli A.Resistance plasmid families in Enterobacteriaceae.Antimicrob. Agents Chemother. 2009; 53: 2227-2238. https://doi.org/10.1128/AAC.01707-08

14. Dandekar T, Dandekar G. Pharmacogenomic strategies against microbialresistance: from bright to b l e a k to i n o vative . Pharmacogenomics 2010; 11: 1193-1196. https://doi.org/10.2217/pgs.10.18

15. Conly JM, Johnston BL. Where are all the new antibiotics? The new antibiotic paradox. Can. J. Infect. Dis. Med. Microbiol. 2005; 16(3):159-160. https://doi.org/10.1155/2005/892058 